\title{
Pleurodesis with pseudomonas aeruginosa- mannose-sensitive hemagglutinin for pneumothorax secondary to COPD: a retrospective study
}

\author{
Hansheng Wu', Dongling Luo', Patrick Y. Tan², Weisheng Wang ${ }^{1}$ and Shaobo Zhang ${ }^{1}$
}

\begin{abstract}
Background: Pneumothorax is a potentially life-threatening complication of chronic obstructive pulmonary disease (COPD) that leads to cardiopulmonary compromise. According to the British Thoracic Society (BTS) guidelines, medical pleurodesis is recommended for inoperable patients suffering from COPD-related pneumothorax. Several sclerosing agents are currently in use, but none have been proven to be the best choice, as each one has effectiveness and safety issues. Recent research has shown that Pseudomonas aeruginosa-mannose-sensitive hemagglutinin (PAMSHA) is a safe bioagent with low toxicity and good immune-boosting effects that can induce the aseptic inflammation necessary to cause pleural adhesion.

The aim of this study is to report our experience using PAMSHA in medical pleurodesis to treat inoperable cases of persistent pneumothorax secondary to COPD.
\end{abstract}

Methods: Records of 78 inoperable patients with persistent pneumothorax secondary to COPD treated with PAMSHA pleurodesis were retrospectively reviewed. Pleurodesis was performed by administering $1 \mathrm{ml}$ of PAMSHA (mixed with lidocaine and 30-40 ml of normal saline) intrapleurally.

Results: The resolution of pneumothorax was observed in all of the patients treated with PAMSHA pleurodesis (success rate $=100 \%$ ). Some of them experienced mild chest pain and fever, but no long-term side effects were reported.

Conclusion: Our data suggest that PAMSHA pleurodesis is a safe and effective option for the treatment of persistent pneumothorax secondary to COPD.

Keywords: PAMSHA, Intrapleral injection, Chronic obstructive pulmonary disease, Secondary spontaneous pneumothorax

\section{Background}

Secondary spontaneous pneumothorax (SSP) occurs as a complication of certain lung diseases, the most common of which is chronic obstructive pulmonary disease (COPD). Approximately $50-70 \%$ of SSP cases are attributed to COPD [1-4], and SSP in COPD occurs when subpleural bullae form and eventually rupture. This leads to persistent

\footnotetext{
*Correspondence: 37370829@qq.com

${ }^{1}$ Department of Cardiothoracic Surgery, First Affiliated Hospital of Shantou University Medical College, No. 57 Changping Road, Shantou City, Guangdong Province 515000, China

Full list of author information is available at the end of the article
}

air leakage into the chest and worsens the symptoms of dyspnea already caused by COPD. According to the British Thoracic Society (BTS) guidelines, the management of SSP includes oxygen supplementation, the insertion of a chest drain, and active intervention by thoracic surgery. However, among patients with SSP who are unfit for surgery, medical pleurodesis is offered as an appropriate alternative [5]. Despite the attractiveness of this non-surgical approach, its indication and the selection of the sclerosing agents used for the procedure are still debated, and the results are poorly defined. 
To help shed more light on this matter, we present our study of the use of Pseudomonas aeruginosamannose-sensitive hemagglutinin (PAMSHA) for the pleurodesis of patients with pneumothorax secondary to COPD. We hope that this report will add knowledge of the ways in which SSP is treated.

\section{Methods}

\section{Study design and ethics board approval}

Records of patients who underwent PAMSHA pleurodesis at our hospital's surgical ward from January 2011 to December 2013 were retrieved for the purpose of reviewing the effects of this intervention. The interventions were performed due to an increasing number of recurrent COPD-related pneumothorax cases in the surgery ward of our hospital. After a discussion with colleagues, our surgical team decided to investigate the efficacy and safety of the agent PAMSHA for pleurodesis of these affected patients. With the approval of the department chair and the ethics board/committee of the hospital (The First Affiliated Hospital of Shantou University Medical College Ethics Review Form - Science Research -No. 2015075), we invited patients who had suffered from COPD-related pneumothorax with persistent air leaks for two weeks to enroll in our intervention. According to the enrollment criteria, these patients must have already received treatment for two weeks consisting of the following: thoracostomy tube placement at the time of admission, guideline-recommended antibiotics for their specific conditions, patient-specific cardiopulmonary and nutritional support, and oxygen supplementation. After discussion of the risks and benefits of the procedure, those who enrolled were asked to sign an informed consent form.

\section{Reagents used}

The PAMSHA used was from the Beijing Wanter Biopharmaceutical Company Ltd (Beijing, China). It was in liquid form and packaged as $1.0 \mathrm{ml}$ of solution per ampule. For our intervention, we added $1.0 \mathrm{ml}$ of PAMSHA to a mixture of $50 \mathrm{ml}$ of lidocaine $(5 \mathrm{ml} / 0.1 \mathrm{~g})$ and 30 $40 \mathrm{ml}$ of $0.9 \% \mathrm{NaCl}$ saline solution. All of the mixture was used in each administration.

\section{Procedure of administration and monitoring}

Skin testing for hypersensitivity was performed prior to intrapleural administration of the agent. After skin testing, the sclerosing agent was prepared for administration (aseptic procedures included). With the patient in the supine position, the tube was clamped $10 \mathrm{~cm}$ away from the chest wall. The sclerosing agent was then injected 5-6 $\mathrm{cm}$ proximal to the clamped end, and the puncture site was sealed with adhesive plaster. To evenly distribute the sclerosing agent, each patient was asked to change position in various ways - from left decubitus to right decubitus, from supine to prone position, and with the head and upper chest elevated. The patient assumed each position for $15 \mathrm{~min}$, and the thoracostomy tube was monitored throughout all position changes. As it was possible to aggravate the pneumothorax throughout the procedures due to insufficient drainage of air, all patients were observed and monitored for cardiorespiratory problems. The tube was unclamped and reclamped every 6-8 h post-injection to monitor for air leakage. For patients who did not report severe adverse effects like chest pain and fever after the first injection, repeated injections of $2 \mathrm{ml}$ of PAMSHA (mixed with $30-40 \mathrm{ml}$ of $0.9 \% \mathrm{NaCl}$ and $5 \mathrm{ml}$ of lidocaine) were administered on alternate days (3rd, 5th, etc.) until signs of air leakage were no longer observed in the water-sealed container. If severe adverse effects occurred, a standby supportive therapy plan was put in place, and the repetition of the injections was postponed to 4 to 5 days after. The patients were monitored for improvement through clinical assessments (interviews, self-reports, and physical exams) and imaging studies (chest $\mathrm{x}$-rays), and it was expected that air leakage would not be observed after 3 injections.

\section{Results}

A total of 78 patient records were retrieved, and the patients enrolled in the intervention were between 45 and 89 years of age, with an average age of 58 years. In total, 76 were males, and 2 were females. They were all heavy smokers who had typical symptoms and signs of COPD such as persistent productive cough, decreased chest excursion, absent fremitus, hyperresonance, and diminished breath sounds. They were determined to have poor pulmonary function and deemed inoperable according to different tests (Table 1 ). Their chest $\mathrm{x}$-rays and CT scans showed pneumothorax, diffuse emphysema, and subpleural bullae. Complications were also noted in these patients. Among them, 15 had bronchiectasis; 35 had latent tuberculosis (TB) infections; 22 had mild abnormalities of liver and kidney function; $16 \mathrm{had}$

Table 1 Results of the selected diagnostic tests

\begin{tabular}{|c|c|}
\hline Clinical parameters & $\begin{array}{l}\text { Frequency } \\
\text { [Percentage }(n)]\end{array}$ \\
\hline $\begin{array}{l}\text { Hypercarbia }\left(\mathrm{PaCO}_{2}>45 \mathrm{mmHg}\right) \\
\text { and hypoxemia }\left(\mathrm{PaO}_{2}<55 \mathrm{mmHg}\right) \\
\text { based on arterial blood gas analysis }\end{array}$ & $82 \%(64)$ \\
\hline $\begin{array}{l}\mathrm{VC}<1 \mathrm{~L}(<50 \% \text { of the predicted value), } \\
\mathrm{FEV} \mathrm{V}_{1}<0.5 \mathrm{~L}(<40 \% \text { of the predicted value), } \\
\mathrm{MW}<50 \% \text { of the predicted value, } \\
\mathrm{FEV}{ }_{1} N C<0.7 \text { in pulmonary function tests }\end{array}$ & $98 \%(76)$ \\
\hline $\begin{array}{l}\text { Confirmed pneumothorax with diffuse } \\
\text { emphysema and subpleural bullae from } \\
\text { CT or chest X-ray }\end{array}$ & $100 \%(78)$ \\
\hline Breath-holding test $<15 \mathrm{~s}$ & $95 \%(74)$ \\
\hline
\end{tabular}

Abbreviations: FEV1 Forced expiratory volume in one second, MVV maximal voluntary ventilation, VC vital capacity 
ischemic heart diseases with pulmonary P waves on ECG; and 73 had elevated white blood cell counts.

All of the patients had undergone thoracostomy tube placement at the time of their admission, and they had also been provided with other supportive measures such as oxygen supplementation, cardiopulmonary stabilization, and infection control using guideline-recommended antibiotics.

After two weeks of standard treatment, the patients with persistent air leakage were administered injections of the PAMSHA mixture. Excluding the lidocaine and saline mixture, the average volume of PAMSHA used for each patient was $5 \mathrm{ml}$ (administered over a period of 7 to 9 days). To reduce recurrence, another $2 \mathrm{ml}$ of PAMSHA (together with the lidocaine and normal saline mixture) was injected. (This was still administered despite the resolution of the pneumothorax on imaging studies.) The frequency of administration was based on the clinical assessments (symptoms and physical examinations) and the results of the chest $\mathrm{x}$-rays. After pleurodesis, $\mathrm{x}$-ray and $\mathrm{CT}$ scans of the chest were requested, and these showed the re-expansion of the affected sides (Figs. 1 and 2). We considered this to be a sign of the resolution of the pneumothorax. These radiographic results were supported by the improvement of the respiratory symptoms in the patients. Based on the physical examination, it was further noted that the hyperresonant sounds were reduced, and the breath sounds improved. During this period, 51 patients experienced mild but transient chest pain and fever, and 3 complained of severe chest pain and dyspnea (Table 2). These patients were given oxygen supplementation, intravenous steroid injections, and oral indomethacin, and they reported the improvement of their symptoms.
Adverse effects such as appetite changes, renal failure, and liver impairment were not reported. After a year of followup, none of the participants reported being readmitted for a pneumothorax, and none of them were reported to have died from any cause.

\section{Discussion}

COPD is a severe lung disease characterized by persistent airflow limitation that progresses over time. In China, it has a prevalence rate of $8.2 \%$ in those over 40 years of age. Diffuse emphysema and subpleural bullae are often found on chest $\mathrm{x}$-rays, and these bullae are the main causes of persistent air leakage, which is difficult to treat. Once air leakage occurs, it devastates the patients because their baseline lung function becomes more limited, and it pushes them to undergo a surgical procedure under general anesthesia [2]. The post-operative complications could also jeopardize their general condition, so the management of pneumothorax secondary to COPD is complicated. Furthermore, patients with this condition could suffer from pneumonia and respiratory failure after lung volume reduction surgery, making it difficult for them to be weaned from ventilators.

The main objective of management of patients with COPD complicated by pneumothorax is to stop air leaks using relatively simple and safe methods, and various methods have been used to meet this objective. If a patient is still in good condition and an operation is tolerable, surgical removal of the subpleural bullae is considered the first line treatment. This prevents the enlarging bullae from gradually compressing the normal lung tissues. However, surgical intervention appears to be a radical
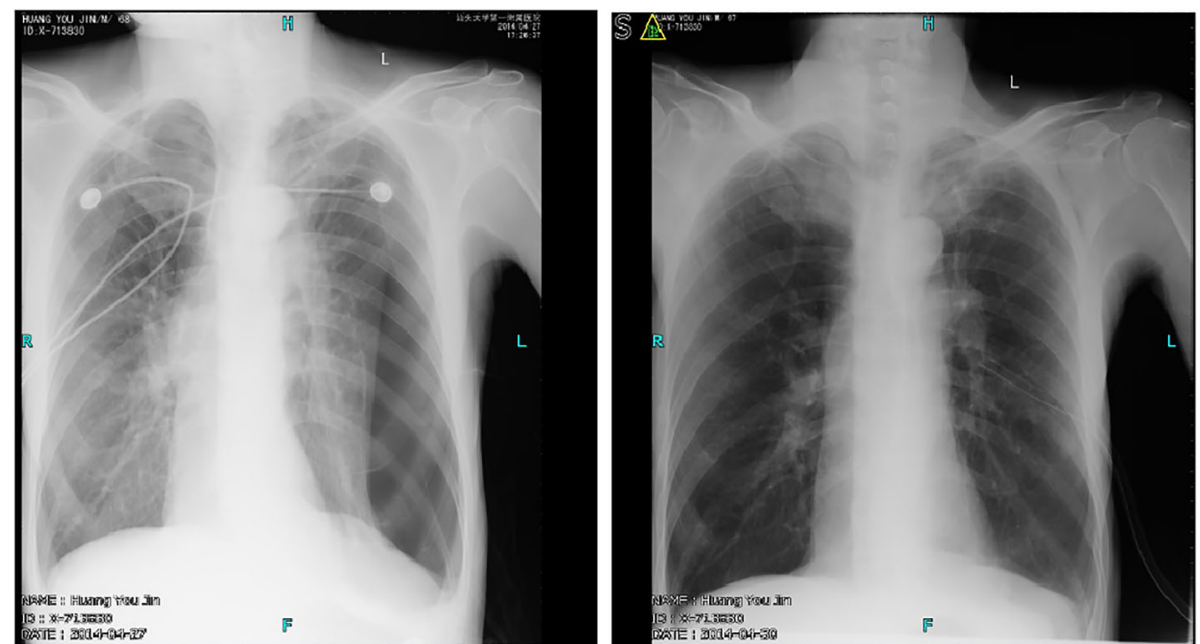

Fig. 1 Chest x-rays of one of our patients before and after PAMSHA therapy. This was a 67-year-old man who was admitted to our hospital for sudden dyspnea for one day. Based on detailed history collection and ancillary tests, COPD was confirmed. The picture on the left is the initial chest X-ray showing severe pneumothorax affecting half of his left lung. After two weeks of hospitalization, PAMSHA was injected intrapleurally. The picture on the right is the chest X-ray from 1 week after PAMSHA injection. It shows the complete removal of the gas and re-expansion of the lung. This confirmed the effectiveness of the method, and no severe adverse effects were reported in this patient 

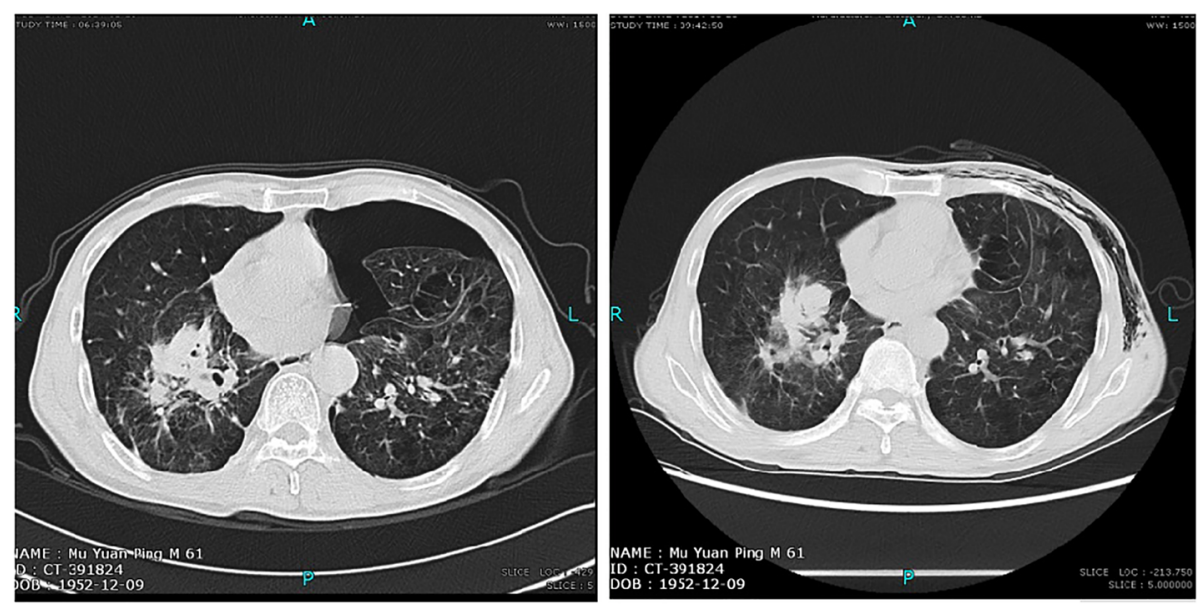

Fig. 2 CT scans of one of our patients before and after PAMSHA therapy. This was a 61-year-old man who presented with shortness of breath and a history of COPD. His initial chest CT (image on the left) showed a lot of free gas in the pleural space and bullae in the left side of the lung. General support, including oxygenation and antimicrobials, was provided to this patient before PAMSHA pleurodesis, and 5 days after PAMSHA injection, his breathing improved. A repeat chest CT scan was performed that showed the disappearance of the free gas in his chest and full re-expansion of the previously compressed lung (right image)

method for recurrent pneumothorax, and there are patients who cannot undergo such a procedure. The management of COPD-related pneumothorax by bronchial occlusion in combination with talc powder has been reported to be successful in three cases [6]. Though no recurrences were observed for more than 1 year, the long hospitalization and complex procedure associated with it made it less favorable. Tube thoracostomy is effective in providing symptomatic improvement, but when it is repeated, it can be a physical and emotional burden to the patients. Another method is to rub the pleural membranes during surgical intervention, which leads to pleural adhesion and prevents the recurrence of pneumothorax. According to the BTS guidelines, medical pleurodesis remains the first choice for treating persistent air leakage [5], as it is safe and easy to perform. It induces pleural adhesion through aseptic inflammation and is indicated for patients with near-normal pulmonary function and no obvious bullae on $\mathrm{CT}$ imaging. However, the use of this method has problems, as there is no consensus yet on the best technique to follow. Additionally, the sclerosing agents used for this procedure have variable efficacy and safety.

Table 2 Incidence of main short-term side effects

\begin{tabular}{ll}
\hline Complications / Intervention & $\begin{array}{l}\text { Patients (78) } \\
\text { [Percentage }(n)]\end{array}$ \\
\hline Fever only $\left(<38.5^{\circ} \mathrm{C}\right) /$ observation & $28.2 \%(22)$ \\
$\begin{array}{l}\text { Mild chest paint only / given oral indomethacin } \\
\text { Fever }\left(>38.5^{\circ} \mathrm{C}\right) \text { and chest pain / oxygen }\end{array}$ & $23.7 \%(18)$ \\
$\begin{array}{l}\text { uptake, oral indomethacin } \\
\text { Severe chest pain and dyspnea / oxygen } \\
\text { uptake, intravenous steroid injections, } \\
\text { and oral indomethacin }\end{array}$ & $14.1 \%(11)$ \\
\hline
\end{tabular}

A recent meta-analysis confirmed the superiority of talc as a sclerosing agent. Talc use can induce intense intrapleural inflammation by producing numerous profibrotic factors that cause adhesions and fibrosis between the pleural membranes [7]. Common side effects of talc include fever (10-17\%), pain, and gastrointestinal symptoms. Less common side effects include arrhythmia, dyspnea, respiratory failure, a systemic inflammatory response, empyema, and the dissemination of talc to other regions [8-10]. However, talc particles and other pro-fibrotic factors hypothetically have the potential to be absorbed and lead to systemic inflammation. This problem has raised questions about the safety of talc as a sclerosing agent [10]. Therefore, scientists are still searching for the most suitable sclerosing agent for pleurodesis - one that could yield a high success rate with a low risk of severe adverse reactions.

Mannose-binding hemagglutinins in extracts of Pseudomonas aeruginosa were first proposed in 1977 and have now gained more consideration because of their anti-tumor effects [11]. Pseudomonas aeruginosamannose-sensitive hemagglutinin (PAMSHA) is a peritrichous $\mathrm{P}$. aeruginosa strain with MSHA fimbriae that can inhibit activation of the epidermal growth factor receptor signaling pathway in tumor cells [12]. Animal studies have shown that PAMSHA affects both the proinflammatory and anti-inflammatory processes, which help limit the severe adverse reactions caused by systemic inflammation [13]. In other studies, it has been reported to induce apoptosis in tumor cells and improve immune function, which can prevent metastasis and the recurrence of certain types of cancer [14-19]. It has also been used to treat malignant pleural effusion [20-22]. 
In this study, we report our experience performing pleurodesis using PAMSHA as the sclerosing agent. We think that this method is more convenient than bronchial occlusion followed by the addition of talc powder. Medical pleurodesis with PAMSHA can produce similar results but without the risk of severe side effects and the trouble of doing a multi-step procedure. After observing the effects of the intrapleural administration of PAMSHA in 78 inoperable cases of pneumothorax secondary to COPD, our follow-up imaging studies showed signs of resolution of the pneumothorax. After a year of followup, none of our patients reported readmission due to recurrence of a pneumothorax. For us, this is enough information to report that we had a success rate of $100 \%$ for the procedure. Additionally, adverse effects such as chest pain and low-grade fever were only transient and resolved well with supportive care. No gastrointestinal and neurologic dysfunction, bone marrow inhibition, or liver/kidney impairment were reported.

There are limitations to this study. First, this study was retrospective, and there was no standardized evaluation of the inoperability of the patients from the perspective of pulmonary function. Second, the reporting of adverse effects after pleurodesis was relatively subjective and did not employ standardized scoring systems to quantify clinical improvement properly. We believe that a prospective study with precise definitions of the variables and a standardized treatment protocol will be helpful in validating our results.

\section{Conclusion}

Pleurodesis is an appropriate treatment for pneumothorax secondary to COPD. However, choosing a highly effective and safe sclerosing agent for this procedure is still controversial. Clinician preferences, agent characteristics (efficacy and safety), and commercial availability are factors that contribute to the selection of a sclerosing agent.

Given the success rate and minimal amount of minor complications reported, we conclude that PAMSHA is an effective and safe sclerosing agent that can be used to treat patients who have pneumothorax secondary to COPD. However, further studies are needed to confirm our conclusion.

\section{Acknowledgement}

The authors would like to thank the Surgery Department of the First Affiliated Hospital of Shantou University Medical College for their support of this project. This work was supported by the Science and Technology Planning Project (No. 2015-37) of the Shantou Municipal Science and Technology Bureau.

\section{Authors' contributions}

HW was the primary investigator of the study. He did all the treatment procedures at the wards, conceptualized the study, reviewed and collected data from the medical records, analyzed the results, and wrote the abstract, background, results and conclusion parts of the manuscript. DL assisted HW in conducting the treatment procedures, did the literature review, and wrote the discussion and reference list of the manuscript. PYT wrote the method part of the manuscript, helped analyzed the results, and revised the manuscript for third party editing and subsequent submission. WW and SZ assisted HW at the wards, reviewed some of the medical records, and collected data for Table 2. All authors read and approved the final manuscript.

\section{Competing interest}

The authors declared that they have no competing interests.

\section{Author details}

${ }^{1}$ Department of Cardiothoracic Surgery, First Affiliated Hospital of Shantou University Medical College, No. 57 Changping Road, Shantou City,

Guangdong Province 515000, China. ${ }^{2}$ Shantou-Oxford Clinical Research Unit (SOCRU), Shantou University Medical College, No. 22 Xinling Rd, Shantou, Guangdong Province 515041, China.

Received: 3 April 2016 Accepted: 2 January 2017

Published online: 10 January 2017

\section{References}

1. Decker D, Tolba R, Springer W, et al. Abdominal surgical interventions:local and systemic consequences for the immune systemaprospective study on elective gastrointestinal surgery [J]. J Surg Res. 2005;126(1):12-8.

2. Noppen M, De Keukeleire T. Peumothorax. Respiration. 2008;76:121.

3. Chen CH, Liao WC, Liu YH, et al. Secondary spontaneous pneumothorax: which associated conditions benefit from pigtail catheter treatment? Am J Emerg Med. 2012;30:45.

4. Guo Y, Xie C, Rodriguez RM, Light RW. Factors related to recurrence of spontaneous pneumothorax. Respirology. 2005;10:378

5. Henry M, Arnold T, Harvey J. Pleural Diseases Group, Standards of Care Committee, British Thoracic Society. BTS guidelines for the management of spontaneous pneumothorax. Thorax. 2003;58 suppl 2:ii39-52.

6. Ishida A, Kida H, Muraoka H, Nishine H, Mineshita M, Miyazawa T. Intractable pneumothorax managed by talc pleurodesis and bronchial occlusion with spigots. Respiry Case Rep. 2015;3(1):13-5.

7. Genofre EH, Marchi E, Vargas FS. Inflammation and clinical repercussions of pleurodesis induced by intrapleural talc administration. Clinics (Sao Paulo). 2007;62:627.

8. Shaw P, Agarwal R. Pleurodesis for malignant pleural effusions. Cochrane Database Syst Rev. 2004;(1):CD002916.

9. Laisaar T, Palmiste V, Vooder T, Umbleja T. Life expectancy of patients with malignant pleural effusion treated with video-assisted thoracoscopic talc pleurodesis. Interact Cardiovasc Thorac Surg. 2006;5:307.

10. Viallat JR, Rey F, Astoul P, Boutin C. Thoracoscopic talc poudrage pleurodesis for malignant effusions. A review of 360 cases. Chest. 1996;110:1387.

11. Gilboa-Garber N, Mizrahi L, Garber N. Mannose-binding hemagglutinins in extracts of Pseudomonas aeruginosa. J Biochem. 1977;55(9):975-81.

12. Chang $L$, Xiao $W$, Yang $Y$, et al. Pseudomonas aeruginosa-mannose-sensitive hemagglutinin inhibits epidermal growth factor receptor signaling pathway activation and induces apoptosis in bladder cancer cells in vitro and in vivo[J]. Urol Oncol. 2014;32(1):e11-18.

13. Zhu H, Wang S, Shen L, Wang W, et al. Effects of Pseudomonas aeruginosa mannose-sensitive hemagglutinin (PAMSHA) pretreatment on septic rats. Int Immunopharmacol. 2013;17(3):836-42.

14. Cao Z, Shi L, Li Y, Wang J, Wang D, Wang G, Sun B, Mu L, Yang M, Li H. Pseudomonas aeruginosa: mannose sensitive hemagglutinin inhibits the growth of human hepatocarcinoma cells via mannose-mediated apoptosis. Dig Dis Sci. 2009;54(10):2118-27.

15. Li T, Dong ZR, Guo ZY, Wang CH, Zhi XT, Zhou JW, Li DK, Chen ZT, Chen $Z Q$, Hu SY. Mannose-mediated inhibitory effects of PAMSHA on invasion and metastasis of hepatocellular carcinoma via EGFR/Akt/lkt/NF-kB pathway. Liver Int. 2015:35(4):1416-29.

16. Liu ZB, Hou YF, Di GH, Wu J, Shen ZZ, Shao ZM. PAMSHA inhibits proliferation and induces apoptosis through the up-regulation and activation of caspases in the human breast cancer cell lines. J Cell Biochem. 2009;108(1):195-206

17. Zhang ZM, Dai HB, Zhou Q. Effects on Lymphocytes apoptosis and immune funtion after stimulating K562 cell lines with Pseudomonas aeruginosamannose-sensitive hemagglutinin [J]. China J Pharmacol. 2007:42(16):12224-7. 
18. Ling W, Liu H, Cao H, et al. Pseudomonas aeruginosa-mannose-sensitive hemagglutinin prevents recurrence and metastasis post-gastectomy []]. China Pract J Surg. 2009;11(29):933-6.

19. Hao W, Yi L, Li-li T. Pseudomonas aeruginosa-mannose-sensitive hemagglutinin for cancerous ulceration of breast cancer. ZhongNan Pharm. 2010;8(1):64-6.

20. Mateen HU, Francisco AA, Mona GS, et al. Management of malignant pleural effusions [J]. Adv Ther. 2010;27(6):334-47.

21. Li WAN, Geng-jing HE. Clinical observation for Pseudomonas aeruginosamannose-sensitive hemagglutinin use in malignant pleural effusion. Clin Lung J. 2013;18(3):401-2.

22. Feixue S, Xiaxia P, Qimei J, Yan P, ZHAO J, Ji XIE. Effects for Pseudomonas aeruginosa-mannose-sensitive hemagglutinin use in malignant pleural effusion [J]. China Clin Tumor. 2013:40(18):1127-9.

Submit your next manuscript to BioMed Central and we will help you at every step:

- We accept pre-submission inquiries

- Our selector tool helps you to find the most relevant journal

- We provide round the clock customer support

- Convenient online submission

- Thorough peer review

- Inclusion in PubMed and all major indexing services

- Maximum visibility for your research

Submit your manuscript at www.biomedcentral.com/submit
Biomed Central 